\title{
Underlying Promotion Mechanism of High Concentration of Silver Nanoparticles on Anammox Process
}

\author{
Meng-Wen Peng1, Xiu-Ling Yu2, Yong Guan 3, *, Peng Liu4, \\ Peng Yan1, Fang Fang1, Jinsong Guo1, You-Peng Chen1, *
}

1 Key Laboratory of the Three Gorges Reservoir Region's Eco-Environments of MOE, Chongqing University, Chongqing 400045, China.

2 Zhejiang Provincial Key Laboratory of Agricultural Resource and Environment, Zhejiang University, Hangzhou 310058, China

3 National Synchrotron Radiation Laboratory, University of Science \& Technology of China, Hefei 230026, China.

4 School of Environmental Studies, China University of Geosciences, Wuhan 430074 , China. 


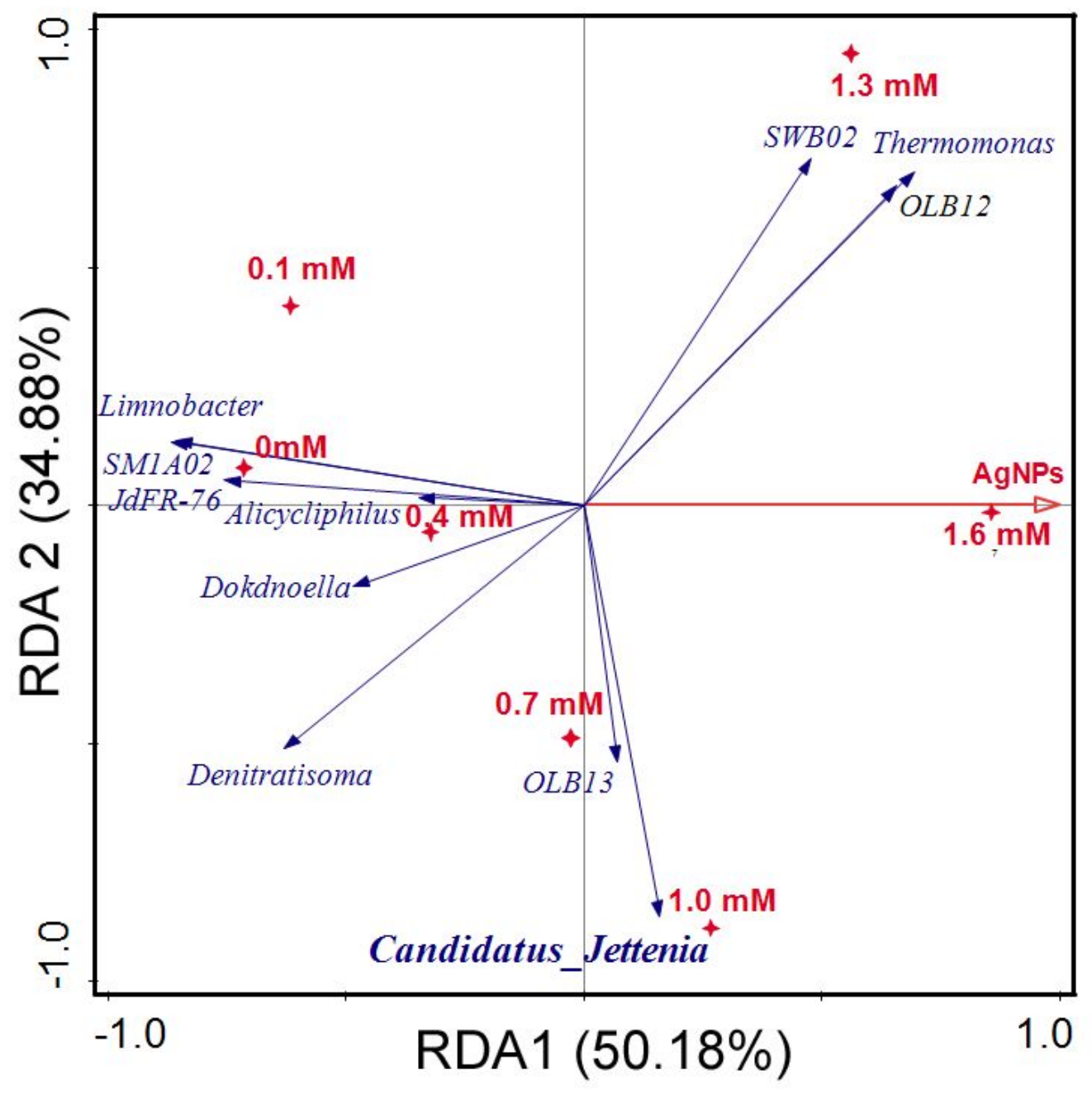

Figure S1. Response of dominant bacteria in anammox granules to different AgNPs. 

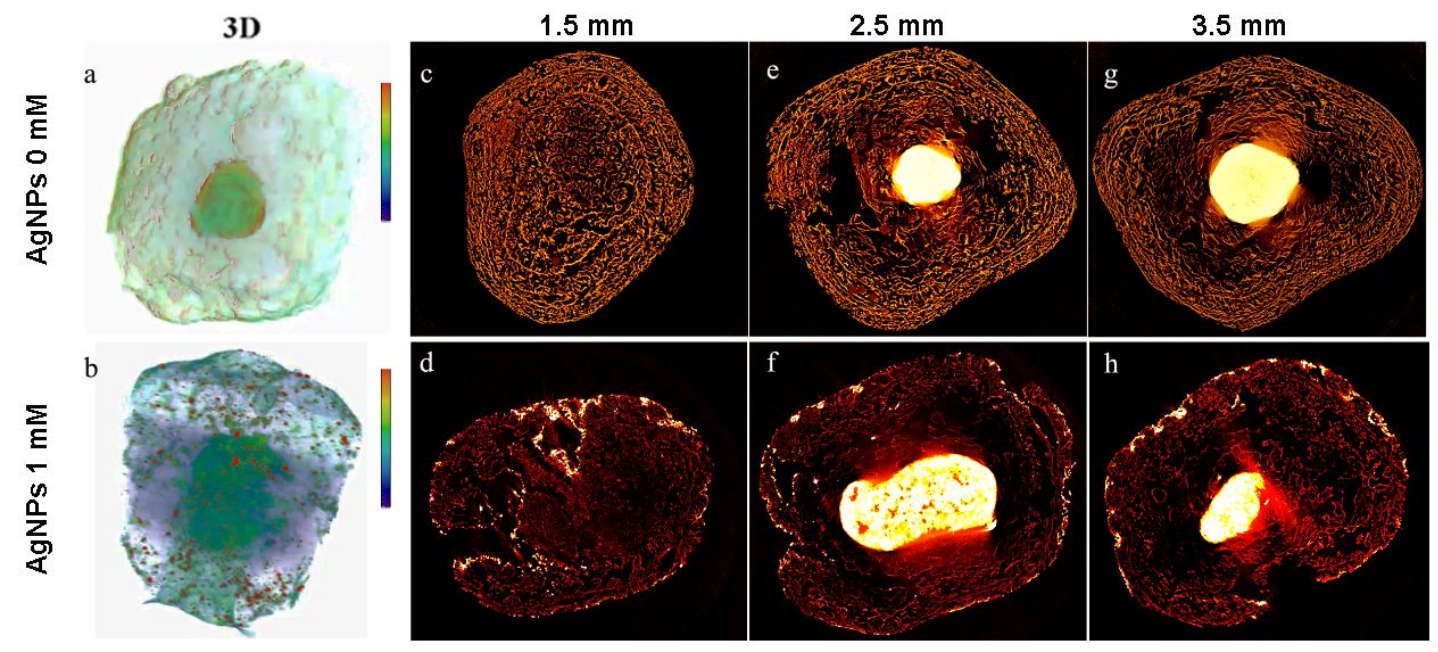

Figure. S2. X-ray tomography of anammox granules at AgNPs concentration of $0 \mathrm{mM}$ and 1 mM. 3D reconstruction of anammox granules at AgNPs concentrations of $0 \mathrm{mM}$ (a) and $1 \mathrm{mM}$ (b). Slice images of the anammox granules at a depth of $1.5 \mathrm{~mm}$ at AgNPs concentrations of 0 $\mathrm{mM}(\mathrm{c})$ and $1 \mathrm{mM}(\mathrm{d})$. Slice images of anammox granules at a depth of $2.5 \mathrm{~mm}$ at AgNPs concentrations of $0 \mathrm{mM}$ (e) and $1 \mathrm{mM}(\mathrm{f})$. Slice images of anammox granules at a depth of 3.5 $\mathrm{mm}$ at $\mathrm{AgNPs}$ concentrations of $0 \mathrm{mM}(\mathrm{g})$ and $1 \mathrm{mM}(\mathrm{h})$. 


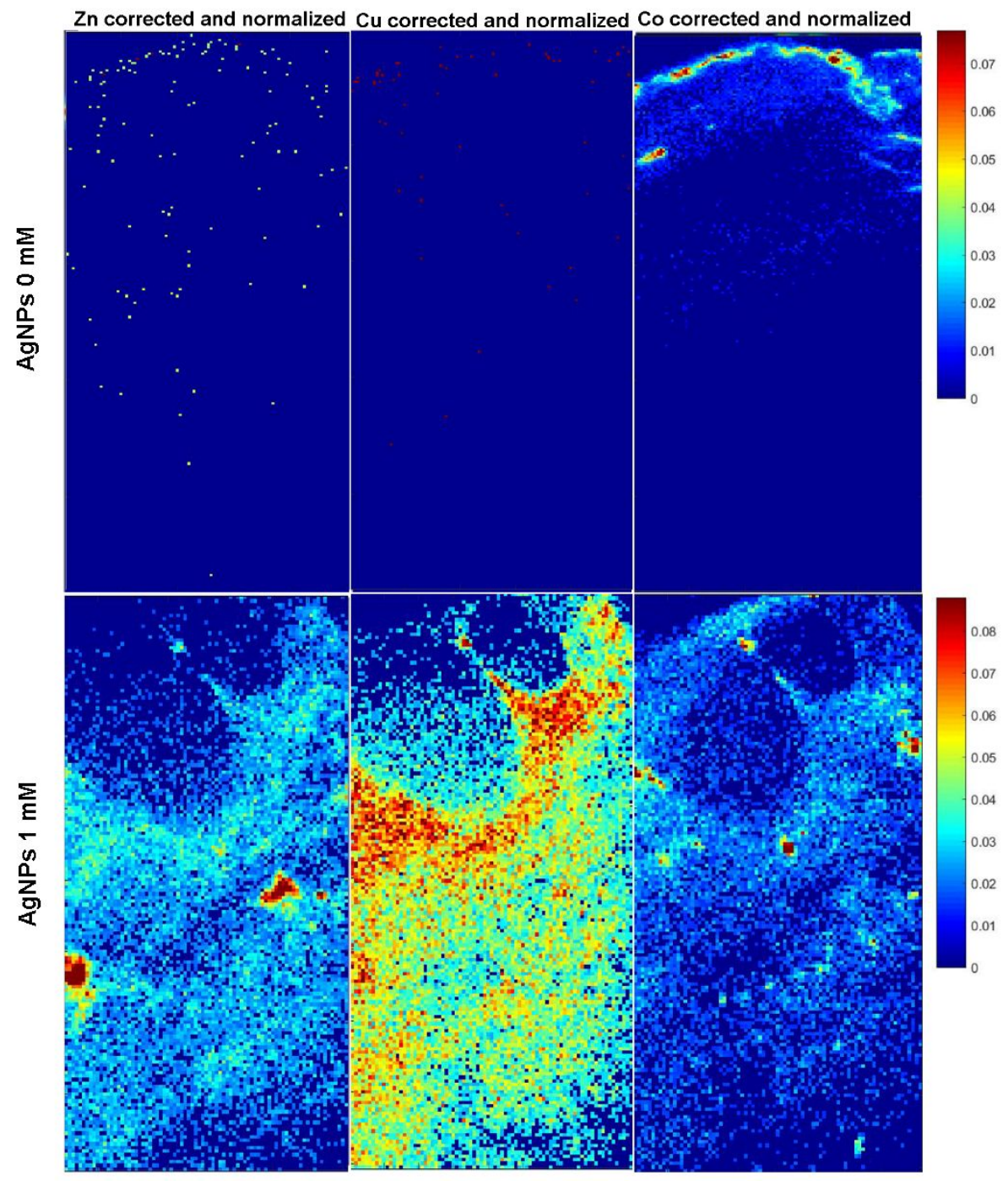

Figure S3. Synchrotron confocal XRF imaging of the $\mathrm{Zn}, \mathrm{Cu}$, Co elements in anammox granules at AgNPs concentrations of $0 \mathrm{mM}$ and $1 \mathrm{mM}$. 


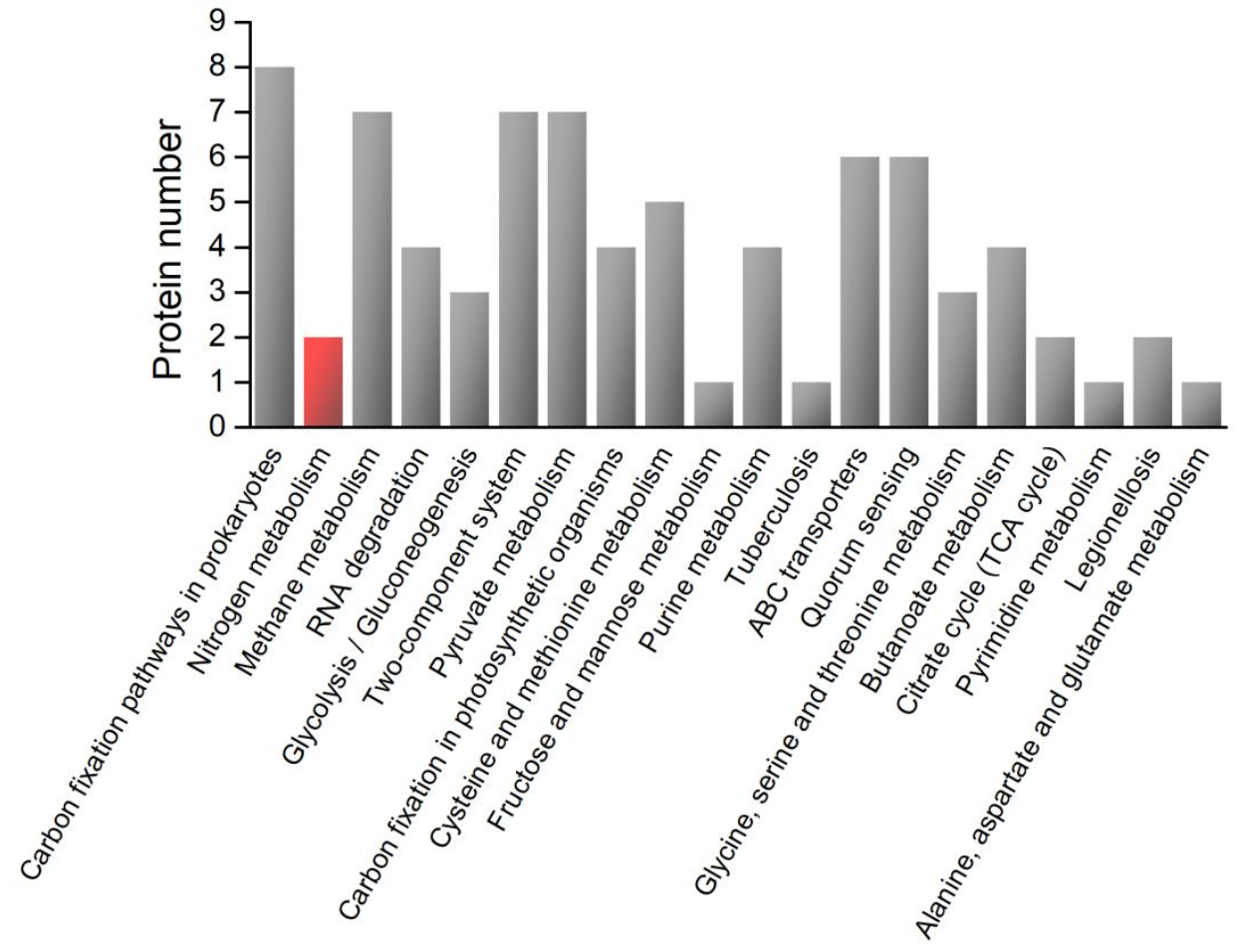

Down-regulated protein in KEGG pathways

Figure. S4. Down-regulated proteins in KEGG pathways. 